\title{
Clinical evaluation of COVID-19/SARS-CoV-2 diagnostic testing in asymptomatic urology patients: implications for resumption of elective surgical care
}

\author{
Jiping Zeng ${ }^{1}$ (D) Ava Wong ${ }^{1} \cdot$ Grant Pollock $^{1} \cdot$ Juan Chipollini ${ }^{1}$
}

Received: 16 August 2020 / Accepted: 21 August 2020 / Published online: 31 August 2020

(c) Springer-Verlag GmbH Germany, part of Springer Nature 2020

\section{Dear Editor,}

The novel coronavirus disease (COVID-19) has impacted almost every healthcare system worldwide. Due to the priority of containing the spread, elective surgeries were largely suspended in many affected areas. Urology has been one of the most impacted surgical specialties with significant clinical implications. As states across the United States (US) have begun to undergo phased re-opening, healthcare systems are having to adapt on the evolving situations and safely resume elective surgeries. Our institution has implemented universal screening for patients whose procedures delaying greater than 30 days may negatively impact outcomes. Herein, we report the feasibility and safety of a system-wide approach using SARS-COV-2 microbiologic testing to ensure a safe return of elective procedures that can be used as reference for other centers aiming to increase surgical capacity.

Between May 1st and May 31st, 2020, a total of 153 cases were performed at Banner-University Medical Center facilities in Tucson, Arizona, US. Institutional IRB was obtained (protocol number 2006792802). All patients were screened for COVID-19 symptoms by a dedicated anesthesia nurse by phone for symptoms. Additionally, a history of diabetes, COPD, CAD, and use of immunosuppressants were recorded for risk stratification. All patients underwent nasopharyngeal swab for SARS-CoV-2 polymerase-chain reaction (PCR) as well $\operatorname{IgM}$ and $\operatorname{IgG}$ antibody tests within 7 days of the scheduled surgery. Those whose PCR test returned negative were asked to self-isolate until the day of surgery. Patients with positive antibody and negative PCR test were asked to obtain a repeat negative PCR test prior to proceeding with surgery. If the PCR test was positive, patients were asked to self-quarantine as per CDC guidelines [1]. Because falsenegatives may occur with testing, droplet precautions were used by peri-operative staff on all cases.

Of the 153 patients who underwent surgeries, the median age was 63 (range 13-85) and 58\% were male (Table 1). $63(41.2 \%)$ have risk factors for immune dysfunction. One patient was diagnosed with COVID-19 by PCR test. He resided in a skilled nursing facility and was later tested as $\mathrm{IgG}$ positive but negative PCR test. He was then allowed to proceed with surgery. We had one patient who developed symptoms 9 days after surgery with positive PCR test. He subsequently required intubation in intensive care unit. None of the care team members were diagnosed with COVID-19 at the end of this study period.

As SARS-CoV-2 may spread in asymptomatic patients, universal testing for all incoming surgical patients is required [2]. We believe a safe return of elective surgeries has three main requirements to fulfil: (1) the risk to contract COVID19 during the operation and hospitalization should be minimal or at least no greater than those outside of hospital; (2) the healthcare workers should be equipped and protected should any positive cases occur; and (3) the hospital must have adequate resources dedicated to the care of COVID-19 patients. As seen in our high-risk cohort of urology patients, our outlined approach has demonstrated initial feasibility for the safe return of elective surgical procedures.

Juan Chipollini

jchipollini@surgery.arizona.edu

1 Department of Urology, The University of Arizona College of Medicine, 1501 N. Campbell Ave, PO Box 245077,

Tucson, AZ 85724-5077, USA 
Table 1 Patient risk factors and perioperative SARS-CoV-2 diagnostic testing result

\begin{tabular}{|c|c|c|c|c|c|c|c|}
\hline $\begin{array}{l}\text { Age (median, } \\
\text { range) }\end{array}$ & $\mathrm{DM}(n, \%)$ & $\operatorname{COPD}(n, \%)$ & $\mathrm{CAD}(n, \%)$ & $\begin{array}{l}\text { Immuno-suppres- } \\
\text { sant use }(n, \%)\end{array}$ & $\begin{array}{l}\text { Surgery type ( } n \text {, } \\
\%)\end{array}$ & $\begin{array}{l}\text { COVID-19 test } \\
(n, \%)\end{array}$ & $\begin{array}{l}\text { COVID-19 (+) after } \\
\text { surgery }\end{array}$ \\
\hline $63(13-85)$ & $35(22.9 \%)$ & $11(7.2 \%)$ & $12(7.8 \%)$ & $5(3.3 \%)$ & $\begin{array}{l}\text { Oncologic } \\
(27,17.6 \%) \\
\text { Reconstructive } \\
(21,13.7 \%) \\
\text { Endoscopic } \\
(86,56.2 \%) \\
\text { Others } \\
(19,12.4 \%)\end{array}$ & $\begin{array}{l}\operatorname{IgG}(+) \\
(1,0.7 \%) \\
\text { RNA (+) } \\
(0)\end{array}$ & $1(0.7 \%)$ \\
\hline
\end{tabular}

$D M$ diabetes mellitus, $C O P D$ chronic obstructive pulmonary disease, $C A D$ coronary artery disease

Author contribution Protocol/project development: JC. Data collection and analysis: JZ, AW, and GP. Manuscript writing/editing: JZ and JC.

\section{Compliance with ethical standards}

Conflict of interest No conflict of interest.

Research involving human participants and/or animals This is a research involving retrospective review of participants. IRB has been obtained from our institution (2006792802).

Informed consent The informed consent has been waived per IRB.

\section{Reference}

1. Centers for disease control and prevention: symptom-based strategy to discontinue isolation for persons with COVID-19 (2020). https://www.cdc.gov/coronavirus/2019-ncov/community/strategydiscontinue-isolation.html

2. Zhou F, Yu T, Du R, Fan G, Liu Y, Liu Z et al (2020) Clinical course and risk factors for mortality of adult inpatients with COVID-19 in Wuhan, China: a retrospective cohort study. Lancet 395:1054-1062

Publisher's Note Springer Nature remains neutral with regard to jurisdictional claims in published maps and institutional affiliations. 